See Article page 107.

\section{Commentary: Cardiac sarcoma remains a formidable challenge}

\author{
Ana Karen Velez, MD, and Jennifer S. Lawton, MD
}

\begin{abstract}
"We look for medicine to be an orderly field of knowledge and procedure. But it is not. It is an imperfect science, an enterprise of constantly changing knowledge, uncertain information, fallible individuals, and at the same time lives on the line. There is science in what we do, yes, but also habit, intuition, and sometimes plain old guessing. The gap between what we know and what we aim for persists. And this gap complicates everything we do."
\end{abstract}

-Atul Gawande

Despite marvels of medicine and amazing technological advances over the past 40 years, a gap in our knowledge exists regarding the treatment of cardiac sarcomas, no guidelines for treatment exist, and survival time after diagnosis remains far too short.

In this issue of the Journal, Yin and associates ${ }^{1}$ present data regarding 442 patients with primary cardiac sarcoma from a US nationwide cancer database (Surveillance, Epidemiology, and End Results) over a 43-year period. In an attempt to look at the trends in treatment and survival over time, they divided patients into 2 groups: 1973 to $2005(\mathrm{~N}=232)$ and 2006 to $2015(\mathrm{~N}=210)$. They also provide a summary of treatment modalities and a review of the literature on this rare diagnosis.

Because of the extremely low incidence of malignant heart tumors, the understanding of their behavior is largely derived from case reports, single-center studies, and small population studies. Yin and colleagues' study ${ }^{1}$ is the largest and most inclusive, and spans the longest time frame of the available reports to date. Therefore, this review is valuable to our understanding of the disease and the impact of treatment on survival.

From the Division of Cardiac Surgery, Department of Surgery, Johns Hopkins University, Baltimore, Md.

Disclosures: Authors have nothing to disclose with regard to commercial support.

Received for publication Jan 9, 2020; accepted for publication Jan 13, 2020; available ahead of print Jan 22, 2020.

Address for reprints: Jennifer S. Lawton, MD, Johns Hopkins Hospital, 1800 Orleans St, Zayed 7107, Baltimore, MD 21287 (E-mail: jlawton4@jhmi.edu).

J Thorac Cardiovasc Surg 2021;162:116-7

$0022-5223 / \$ 36.00$

Copyright (c) 2020 by The American Association for Thoracic Surgery

https://doi.org/10.1016/j.jtcvs.2020.01.010

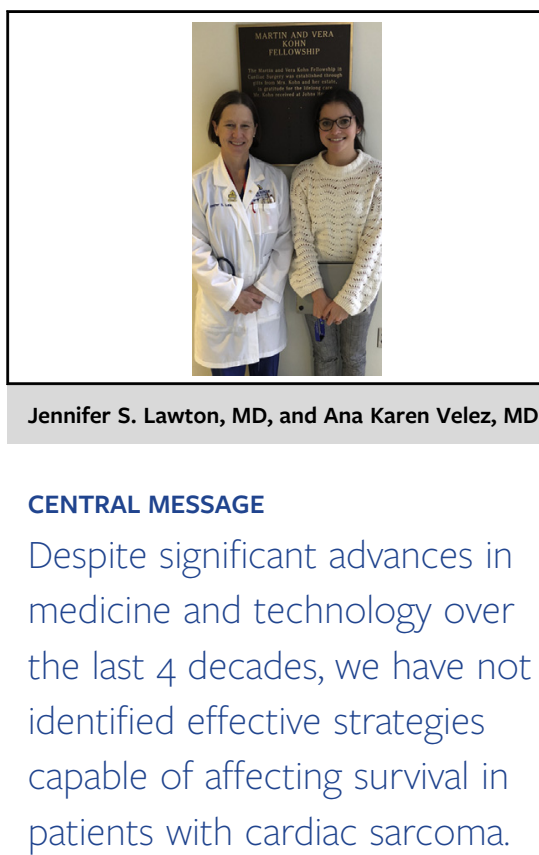

Yin and associates ${ }^{1}$ found that the most common primary malignant cardiac tumor was cardiac angiosarcoma and that median survival was 7 months (with 1-, 3-, and 5-year survivals of $40 \%, 16 \%$, and $10 \%$, respectively), shorter than what previous studies have found. However, as the authors suggest, previous studies had a lesser proportion of cardiac angiosarcomas, had a greater proportion of operable patients, and were conducted at centers of excellence where innovative therapies were available. In the real world, patients often have late presentation, are not candidates for surgery, and may not be treated at a center of excellence. Thus, this study may provide a more translatable estimated median survival applicable to a broader population.

Among the different treatment modalities, both surgery and chemotherapy were found to be independent protective factors, with surgery being the strongest. However, each only increased survival from 4 to 14 months. However, these conclusions must be tempered because of the lack of tumor grade data (available in 241 patients) and lack of tumor staging (available in 198 patients) in this study.

Unfortunately, as the authors note, little significant progress has been made in the treatment of this uncommon disease. They noted that treatment decade did not significantly alter survival. Despite many advances over the 43 years of the study, survival in patients with cardiac sarcoma remains dismal and treatment modalities add little to survival time. Over the past 43 years, novel diagnostic and surgical tools, precision medicine, stem cell research, and genomic mapping have helped to identify weaknesses that have facilitated and successfully treated other 
malignancies with immunotherapy or other unique therapies. Sadly, sarcoma involving the heart has yet to have specific targeted weaknesses identified that can be exploited to reduce its lethality.

Yin and colleagues ${ }^{1}$ appropriately highlight the importance of conducting updated, large population, multicenter reviews and the need to acquire new weapons and strategies to conquer sarcoma of the heart.

\section{Reference}

1. Yin K, Luo R, Wei Y, Wang F, Zhang Y, Karlson KJ, et al. Survival outcomes in patients with primary cardiac sarcoma in the United States. J Thorac Cardiovasc Surg. 2021;162:107-15.e2.
See Article page 107

\section{Commentary: The yet-unsolved problem of effective treatment for primary cardiac sarcomas}

\author{
Joe B. Putnam, Jr, MD, FACS
}

Primary cardiac sarcomas (PCS) are rare and often advanced at diagnosis when symptoms appear. The value of surgery may be limited by a lack of consistent and effective systemic management.

Yin and colleagues ${ }^{1}$ reviewed 442 patients with PCS derived from the Surveillance, Epidemiology, and End Results Program (https://seer.cancer.gov/) between 1973 and 2015. Angiosarcoma was most common histology $(54 \%)$ and had the worst median survival from diagnosis (7 months) compared with all other sarcoma types. Survival did not improve in the most recent treatment decade compared to prior years. Still, chemotherapy and surgery were independently associated with modest improvement in overall survival.

As with any population study, limitations are present. Neither chemotherapy, type of operation, nor the time interval between diagnosis and any treatment was described. Only 46 patients had total resection and 56 patients had no treatment. Tumor size was missing in

\footnotetext{
From Baptist MD Anderson Cancer Center, Jacksonville, Fla. Disclosures: The author reported no conflicts of interest.

The Journal policy requires editors and reviewers to disclose conflicts of interest and to decline handling or reviewing manuscripts for which they may have a conflict of interest. The editors and reviewers of this article have no conflicts of interest.

Received for publication April 1, 2020; revisions received April 1, 2020; accepted for publication April 2, 2020; available ahead of print April 18, 2020.

Address for reprints: Joe B. Putnam, Jr, MD, FACS, Baptist MD Anderson Cancer Center, 1301 Palm Ave, Jacksonville, FL 32207 (E-mail: bill.putnam@bmcjax. com).

J Thorac Cardiovasc Surg 2021;162:117-8

$0022-5223 / \$ 36.00$

Copyright (C) 2020 by The American Association for Thoracic Surgery

https://doi.org/10.1016/j.jtcvs.2020.04.024
}

Check for updates

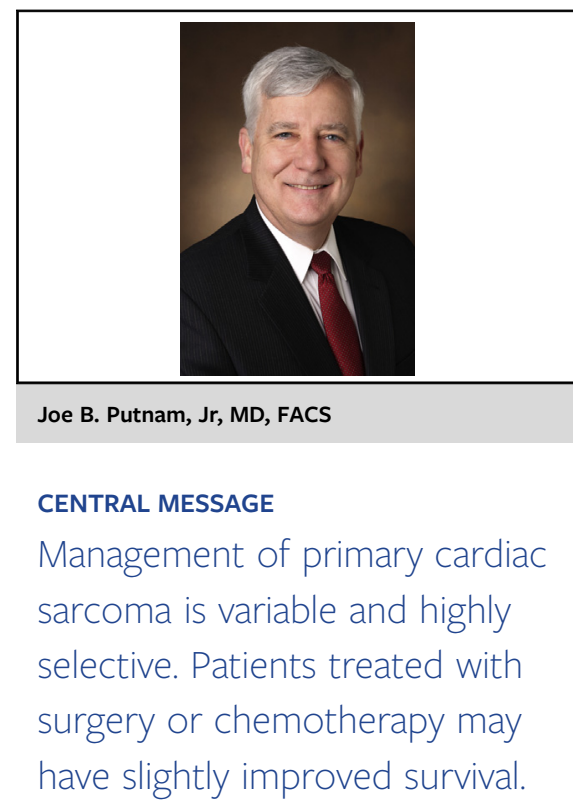

$55 \%$ of patients and tumor grade in $45 \%$. Staging was only available for the 198 patients $(44.8 \%)$ treated after 2000. More than $75 \%$ of these patients were locally advanced (stage III, $21.2 \%$ ) or metastatic (stage IV, 54\%) (American Joint Committee on Cancer 7th edition).

Neither performance status, selection criteria for surgery, nor surgical mortality was presented. Although survival for patients receiving surgery was better than those receiving no surgery, and for younger compared with older patients, this advantage may reflect a selection bias-and survival advantage-for patients who were more fit. Patients with PCS had better survival for the first 2 years with surgery, and with chemotherapy, yet long-term survival was similar.

Hendricksen and colleagues ${ }^{2}$ recently reviewed 617 patients with PCS identified through the National Cancer Database (2004-2015) and found that patients receiving surgery and adjuvant therapy had a 19-month median 